\title{
Magnesium Sulfate: Fetal Neuroprotective Role in Reducing the Risk of Cerebral Palsy
}

\author{
Simona Constantinescu, Margareta Denes, Andrei Chilianu, Radu Vladareanu
}

\begin{abstract}
Advances in perinatal and neonatal medicine have significantly improved survival rates of preterm infants. This improvement has been associated with substantial risk of neurodevelopmental impairments and with increased number of infants with special health care needs. Cerebral palsy is the most well known and potentially most disabling motor abnormality associated with prematurity. There has been limited progress in understanding the causes of cerebral palsy and in developing primary prevention strategies. Several studies have summarized the experimental evidence that supports possible neuroprotective effects of magnesium. Five randomized controlled trials of antenatal magnesium sulfate found a trend of reduced risk of cerebral palsy in preterm infants. Three meta-analyses using the data from these five trials found that magnesium sulfate given to women at risk of premature birth significantly reduced the risk of cerebral palsy without increasing the risk of perinatal or infant death.
\end{abstract}

Keywords: Cerebral palsy, Magnesium sulfate, Neuroprotection, Preterm birth.

How to cite this article: Constantinescu S, Denes M, C hilianu A, Vladareanu R. Magnesium Sulfate: Fetal Neuroprotective Role in Reducing the Risk of Cerebral Palsy. Donald School J Ultrasound Obstet Gynecol 2013;7(1):98-104.

\section{Source of support $\mathrm{Nil}$}

\section{Conflict of interest: None}

\section{CEREBRAL PALSY AND PRETERM BIRTH}

Infants born preterm have a higher risk of neurologic impairments, cerebral palsy (CP) and cognitive dysfunction being the most frequent, and of substantial disability as a result of these impairments.

$C P$ describes a group of disorders affecting the development of movement and posture, causing activity limitation, secondary to nonprogressive disturbances that occurred in the developing fetal or infant brain. The motor disorders are often accompanied by neurodevel opmental or sensory problems, such as seizures, hearing or vision impairments, or behavioral, communicative, and/or cognitive deficits. ${ }^{1}$

The risk of serious medical disabilities such as $C P$, mental retardation and other developmental and behavioral disorders, as well as of other disabilities, such as blindness, hearing loss and epilepsy increases significantly with decreasing gestational age at birth. ${ }^{2}$

The survival rate of very preterm infants who are at higher risk has continued to increase overtime due to advances in perinatal care, and whereas some data suggest that the rate of $\mathrm{CP}$ among survivors has declined, other data suggest that the rate is unchanged or even increasing. ${ }^{2-4}$ The prevalence of $C P$ ranges betw een 1.5 and 3.6 cases per 1,000 live births. ${ }^{5}$

\section{Etiology of Cerebral Palsy}

A full understanding of casual pathways and mechanisms leading to $C P$ remains elusive in many cases at the present time. ${ }^{1}$ In the pathophysiology of brain lesions associated with CP were described prenatal, perinatal and postnatal factors that include hypoxic-ischemic insults, maternal infection with production of proinflammatory cytokines, excessive glutamate release initiating the excitotoxic cascade, oxidative stress, growth factor deficiency, specific drugs and maternal stress. ${ }^{6}$ It is believed that the timing of that insult is in the prenatal or perinatal period in about $70 \%$ of the cases in infants born preterm and $85 \%$ in those born at term, with only 10 to $28 \%$ cases of CP due to birth asphyxia. ${ }^{7}$

Preterm delivery, low birth weight, intrauterine infection/inflammation, multiple gestation, maternal or fetal coagulation disorders, antepartum hemorrhage, and preeclampsia have all been associated with CP.7,8 M oreover, recent studies support the existence of genetic susceptibility factors. ${ }^{6}$ A pproximately one-third of cases of $C P$ are associated with early preterm birth. ${ }^{3}$ The risk of intraventricular hemorrhage increases with the lower the gestational age at birth. ${ }^{9}$

The most prevalent pathological lesion seen in $C P$ is periventricular white matter injury resulting from vulnerability of the immature preoligodendrocytes before 32 weeks of gestation. ${ }^{5}$

Preterm birth is enormous public health concern since many of these preterm infants survive with neurobehavioral, cognitive and motor disabilities. ${ }^{10} \mathrm{~B}$ oth economically and emotionally, the burden of $C P$ is enormous. ${ }^{11}$

\section{Magnesium Sulfate: A Possible Role}

A $n$ association between antenatal exposure to magnesium sulfate $\left(\mathrm{M} \mathrm{gSO}_{4}\right)$ and a reduction in the risk of $\mathrm{CP}$ in infants born very low birth weights was first suggested by a casecontrol study published in $1995 .{ }^{12}$ In this observational study children with CP were significantly less likely to have been 
exposed to $\mathrm{MgSO}_{4}$ in utero during labor than children without $\mathrm{CP}$, suggesting a protective effect of $\mathrm{M} \mathrm{gSO}_{4}$ against $C P$ in these very low birth weight infants [odds ratio (OR) of $C P$ in magnesium exposed fetuses $0.14 ; 95 \%$ confidence interval $(\mathrm{Cl})$ 0.05-0.51]. $\mathrm{M} \mathrm{gSO}_{4}$ had been administered for seizure prophylaxis in pre-eclampsia or as a tocolytic agent.

\section{Magnesium Sulfate: How does it Work?}

$\mathrm{MgSO}_{4}$ is commonly used worldwide in obstetric practice as an anticonvulsant for treatment of eclampsia and for seizure prophylaxis in pre-eclampsia, and is no longer recommended for tocolysis because it is ineffective. ${ }^{13}$

The exact mechanism of action for the neuroprotective effect of $\mathrm{MgSO}_{4}$ in preterm infants is not known. $\mathrm{M} \mathrm{gSO}_{4}$ has been proposed to act as a neuroprotectant through one or many of the following mechanisms: Reduction of inflammatory cytokines or free radicals produced during hypoxic-ischemic reperfusion, prevention of excitotoxic calcium-induced injury, membrane stabilization by preventing the membrane depolarization, inhibition of the glutamate receptors involved in injury to preoligodendrocytes, stabilization of fluctuations in blood pressure that occur in neonates, and an increase in cerebral blood flow. ${ }^{5,7,14,15}$ Other animal data suggest that $\mathrm{M} \mathrm{gSO}_{4}$ may serve an antiapoptotic role and prevent neuronal cell loss. ${ }^{10}$

During asphyxia, there is excessive release and reduced uptake of glutamate in the brain. Glutamate acts on the $\mathrm{N}$-methyl-D-aspartate (N M D A ) receptor, a postsynaptic ion channel, allowing excessive calcium influx into the neurons and inducing neuronal injury. ${ }^{16} \mathrm{~F}$ etal and newborn brains seem to be more susceptible to damage from glutamate release. ${ }^{17}$ Magnesium is a naturally occurring NMDA receptor antagonist that blocks neuronal influx of calcium within the ion channels, preventing posthypoxic brain injury. ${ }^{16}$

By its peripheral vasodilator effects, $\mathrm{M} \mathrm{gSO}_{4}$ can produce flushing, sweating and a sensation of warmth. Reported side effects include nausea, vomiting, headache, pal pitations and rarely pulmonary edema. Administration above the recommended therapeutic levels can lead to respiratory depression, respiratory arrest, cardiac arrest and death. $\mathrm{H}$ ypermagnesemia at neonate can lead to hyporeflexia, poor sucking, and rarely, respiratory depression needing mechanical ventilation. ${ }^{13,17}$

$M$ agnesium readily crosses the placenta, and can be detected in the fetal serum within 1 hour of maternal infusion, and in the amniotic fluid within 3 hours. ${ }^{11}$

Contraindications to $\mathrm{M} \mathrm{gSO}_{4}$ therapy are: Respiratory rate $<16 /$ min, absent patellar reflexes, urine output $<100 \mathrm{ml}$ during the previous 4 hours, renal failure, hypocalcemia. ${ }^{9}$

\section{Randomized Controlled Trials}

A number of randomized controlled trials were performed to assess the efficacy of $\mathrm{MgSO}_{4}$ specifically for fetal neuroprotection in women at risk for preterm delivery. The characteristics of these trials are outlined in Table 1.

$M$ agnesium and neurologic endpoints trial (M agNET) ${ }^{18}$ enrolled 149 women in preterm labor, 25 to 33 weeks of gestation, at a single center from U nited States. The aim of this study was to determine whether the use of antenatal $\mathrm{M} \mathrm{gSO}_{4}$ prevents neonatal intraventricular hemorrhage, periventricular leukomalacia, death and CP. There were two treatment strategies: The tocolytic arm and the neuroprotective arm. For the neuroprotective arm women were randomly allocated to either a $4 \mathrm{gm} \mathrm{M} \mathrm{gSO}_{4}$ bolus or saline placebo. Contrary to original hypotheses, they concluded that the use of antenatal magnesium sulfate was associated with worse, not better, perinatal outcome in a dose-response fashion.

The A ustralasian Collaborative Trial of $M$ agnesium Sulfate ( $\left.\mathrm{ACTOM} \mathrm{gSO}{ }_{4}\right),{ }^{9}$ a placebo controlled trial, included 1,062 women (16 tertiary hospitals from A ustralia and $\mathrm{N}$ ew Zealand) less than 30 weeks of gestation for whom birth was anticipated within 24 hours. Women were randomly assigned to receive either a loading dose of $4 \mathrm{gm}$ intravenous $\mathrm{MgSO}_{4}$ followed by a maintenance infusion of $1 \mathrm{gm} / \mathrm{h}$ (magnesium group) or isotonic sodium chloride solution (placebo group) until delivery or for up to 24 hours. $\mathrm{M} \mathrm{gSO}_{4}$ was given as a neuroprotective agent only and not for tocolysis. The primary outcomes were rates of total pediatric mortality, CP in survivors, and the combined outcome of death and $\mathrm{CP}$ at 2-year follow-up. Compared to controls, the $\mathrm{M} \mathrm{gSO}_{4}$ group had lower rates of total pediatric mortality [13.8 vs $17.1 \%$; relative risk (RR): $0.83 ; 95 \%$ confidence interval (CI): 0.64-1.09], CP (6.8 vs $8.2 \%$; RR: $0.83 ; 95 \%$ $\mathrm{Cl}: 0.54-1.27)$, and combined death and CP (19.8 vs $24.0 \%$; RR: $0.83 ; 95 \% \mathrm{Cl}: 0.66-1.03)$, but none of the differences were statistically significant, although the average size of the reductions in these adverse outcomes are potentially clinically important. Substantial gross motor dysfunction (3.4 vs 6.6\%; RR $0.51 ; 95 \% \mathrm{Cl}: 0.29-0.91$ ) and combined outcome of death or substantial gross motor dysfunction (17.0 vs $22.7 \%$; RR: $0.75 ; 95 \% \mathrm{Cl}: 0.59-0.96$ ) were significantly less frequent among surviving children in the $\mathrm{M} \mathrm{gSO}_{4}$ group. There was little evidence in this trial of any effect of $\mathrm{M} \mathrm{gSO}_{4}$ on the rate of intraventricular hemorrhage or on the rate of cystic periventricular leukomalacia.

The magnesium sulfate for prevention of eclampis trial $(\mathrm{MAGPIE})^{19,20}$ was conducted to assess the effects of in utero exposure to $\mathrm{MgSO}_{4}$ for children whose mothers had pre-eclampsia, and did not look initially at $\mathrm{M} \mathrm{gSO}_{4}{ }^{\prime} \mathrm{s}$ 
Table 1: Randomized controlled trials: Characteristics and neuroprotective conclusions

\begin{tabular}{|c|c|c|c|c|c|}
\hline Study & Centers & $\begin{array}{l}\text { Number of } \\
\text { participants }\end{array}$ & $\begin{array}{l}\text { Gestational } \\
\text { age }\end{array}$ & $\begin{array}{l}\text { Magnesium } \\
\text { regimen }\end{array}$ & Neuroprotective outcomes \\
\hline $\begin{array}{l}\text { MagNET, } \\
\text { Mittendoff et al }{ }^{18}\end{array}$ & 1 (United States) & 149 mothers & 25-33 weeks & $\begin{array}{l}4 \mathrm{gm} \text { bolus } \\
\text { (neuroprotective } \\
\text { arm) }\end{array}$ & $\begin{array}{l}\text { Antenatal } \mathrm{MgSO}_{4} \text { was associated } \\
\text { with worse perinatal otucome }\end{array}$ \\
\hline \multirow[t]{2}{*}{$\begin{array}{l}\text { ACTOMgSO }_{4} \\
\text { C rowther et al }^{9}\end{array}$} & \multirow[t]{2}{*}{$\begin{array}{l}16 \text { (Australia } \\
\text { and New Zealand) }\end{array}$} & \multirow[t]{2}{*}{1,062 mothers } & \multirow[t]{2}{*}{$<30$ weeks } & \multirow[t]{2}{*}{$\begin{array}{l}4 \mathrm{gm} \text { bolus, } \\
1 \mathrm{gm} / \mathrm{h} \\
\text { maintenance }\end{array}$} & $\begin{array}{l}\text { CP RR: } 0.83 ; 95 \% \mathrm{Cl}: 0.54-1.27 \\
\text { Combined outcome of death or } \\
\text { CP RR: } 0.83 ; 95 \% \mathrm{Cl}: 0.66-1.03\end{array}$ \\
\hline & & & & & $\begin{array}{l}\text { Differences were not statistically } \\
\text { significant }\end{array}$ \\
\hline $\begin{array}{l}\text { Magpie trial, } \\
\text { Duley et al }{ }^{19,20}\end{array}$ & 125 (International) & 3,283 children & $<37$ weeks & $\begin{array}{l}4 \mathrm{gm} \text { bolus, } 1 \mathrm{gm} / \mathrm{h} \\
\text { IV maintenance } \\
\text { or, } 4 \mathrm{gm} \text { bolus } \\
\text { combined with } \\
10 \mathrm{gm} \mathrm{IM} \text {, then } \\
5 \mathrm{gm} / 4 \mathrm{hrs} \mathrm{IM} \\
\text { maintenance }\end{array}$ & $\begin{array}{l}\text { Combined death or neurosensory } \\
\text { disability RR: } 1.06 ; 95 \% \\
\text { Cl: } 0.90-1.25 \\
\text { Neurosensory disability at } \\
18 \text { months RR: } 0.72 ; 95 \% \mathrm{Cl} \text { : } \\
0.40-1.29\end{array}$ \\
\hline \multirow[t]{3}{*}{$\begin{array}{l}\text { PreMAG trial + } \\
\text { follow-up trial, } \\
\text { Marret et al }\left.\right|^{21,22}\end{array}$} & \multirow[t]{3}{*}{18 (France) } & \multirow[t]{3}{*}{$\begin{array}{l}573 \text { mothers } \\
\text { (original trial) } \\
472 \text { children } \\
\text { (follow-up trial) }\end{array}$} & \multirow[t]{3}{*}{$<33$ weeks } & \multirow[t]{3}{*}{$\begin{array}{l}4 \mathrm{gm} \text { bolus, no } \\
\text { maintenance }\end{array}$} & $\begin{array}{l}\text { Original trial: Nonsignificant } \\
\text { decrease in risk of short-term } \\
\text { severe white matter injury, } \\
\text { mortality before hospital discharge }\end{array}$ \\
\hline & & & & & $\begin{array}{l}\text { Follow-up trial ( } 2 \text { years): Combined } \\
\text { death or cerebral palsy OR: } 0.65 \text {; } \\
95 \% \mathrm{Cl}: 0.42-1.03\end{array}$ \\
\hline & & & & & $\begin{array}{l}\text { Combined death or gross motor } \\
\text { dysfunction OR: } 0.62 ; 95 \% \\
\text { Cl: } 0.41-0.93 \text { ) (statistically significant) }\end{array}$ \\
\hline \multirow[t]{2}{*}{$\begin{array}{l}\text { BEAM, Rouse } \\
\text { et } \mathrm{al}^{3}\end{array}$} & \multirow[t]{2}{*}{20 (United States) } & \multirow[t]{2}{*}{2,241 mothers } & \multirow[t]{2}{*}{ 24-31 weeks } & \multirow[t]{2}{*}{$\begin{array}{l}6 \mathrm{gm} \text { bolus, } 2 \mathrm{gm} / \mathrm{h} \\
\text { maintenance }\end{array}$} & $\begin{array}{l}\text { Significant decrease in the risk of } \\
\text { moderate or severe CP (RR: } 0.55 \\
95 \% \mathrm{Cl} \text { : } 0.32-0.92 \text { ) among surviving } \\
\text { children in the } \mathrm{MgSO}_{4} \text { group }\end{array}$ \\
\hline & & & & & $\begin{array}{l}\text { Death and CP RR: } 0.97 ; 95 \% \\
\mathrm{Cl}: 0.77-1.23\end{array}$ \\
\hline
\end{tabular}

Cl: Confidence interval; CP: Cerebral palsy; OR: Odds ratio; RR: Relative risk

effect on neurodevelopmental disorders specifically. This study included 125 centers from 19 countries. Women were randomly allocated to receive either $\mathrm{M} \mathrm{gSO}_{4}$ or placebo as an intravenous loading dose followed by 24 hours of maintenance therapy. The primary outcome was the composite measure of death or neurosensory disability at age of 18 months. Of the children whose mothers were allocated $\mathrm{M} \mathrm{gSO}_{4}, 15.0 \%$ had the primary outcome of death or neurosensory disability compared with $14.1 \%$ allocated placebo (RR: 1.06; $95 \% \mathrm{Cl}: 0.90-1.25)$, and of survivors, $1.3 \%$ had neurosensory disability at 18 months compared with $1.9 \%$ (RR: $0.72 ; 95 \% \mathrm{Cl}$ : 0.40-1.29). Fifteen children were identified as having $C P$ (five in magnesium group vs 10 in placebo group).

The PREMAG trial ${ }^{21,22}$ enrolled 573 women less than 33 weeks of gestation who were expected to deliver within 24 hours at 18 collaborating centers in France. The aim of the study was to determine if $\mathrm{M} \mathrm{gSO}_{4}$ given to women at risk of very-preterm birth would be neuroprotective in preterm newborns and would prevent neonatal mortality and severe white-matter injury (detected on neonatal cranial ultrasound). Women were randomly assigned to receive a single $4 \mathrm{gm}$ loading dose of $\mathrm{M} \mathrm{gSO}_{4}$ or placebo, without maintenance infusion. The rates of total mortality before hospital discharge (9.4 vs $10.4 \%$; OR: $0.79 ; 95 \% \mathrm{Cl}: 0.44-$ 1.44 ), severe white-matter injury ( 10.0 vs $11.7 \%$; OR: 0.78 ; $95 \% \mathrm{Cl}: 0.47-1.31$ ), and their combined outcome (16.5 vs 17.9\%; OR: $0.86 ; 95 \% \mathrm{Cl}: 0.55-1.34)$ were all lower for the $\mathrm{M} \mathrm{gSO}_{4}$ compared with placebo group, but no differences were statistically significant. ${ }^{21}$ In the 2-year follow-up of the PREMAG trial 472 children were assessed through clinical examination. There was a strong trend toward a neuroprotective effect of $\mathrm{M} \mathrm{gSO}_{4}$ against combined $\mathrm{CP}$ or death (OR 0.65; 95\% Cl 0.42-1.03). Also, exposure to $\mathrm{MgSO}_{4}$ was protective against combined gross motor 
dysfunction or death (OR: $0.62 ; 95 \% \mathrm{Cl}: 0.41-0.93)$ and achieved significance. ${ }^{22}$

The largest trial, beneficial effects of antenatal magnesium sulfate (BEAM) ${ }^{3}$ enrolled 2,241 women at imminent risk for delivery between 24 and 31 weeks of gestation (20 centers from U nited States). Women were randomly assigned to either $\mathrm{M} \mathrm{gSO}_{4}, 6 \mathrm{gm}$ loading dose followed by an infusion of $2 \mathrm{gm} / \mathrm{h}$, or identical placebo. Follow-up was accomplished in $95.6 \%$ of children. The primary study outcome was the composite of stillbirth or infant death by 1 year corrected age or moderate or severe $\mathrm{CP}$ at or beyond 2 years of corrected age. The rate of the primary outcome was not significantly different in the magnesium group and the placebo group (11.3 vs $11.7 \%$; RR: $0.97 ; 95 \% \mathrm{Cl}: 0.77-1.23)$. They observed significant decrease in the risk of moderate or severe $\mathrm{CP}$ (a prespecified secondary outcome) among surviving children in the $\mathrm{M} \mathrm{gSO}_{4}$ group ( 1.9 vs $3.5 \%$; RR: $0.55 ; 95 \% \mathrm{Cl}: 0.32-0.95$; $p=0.03)$. In terms of gestational age, at randomization ( $<28$ weeks vs $\geq 28$ weeks), only infants of pregnancies randomized at less than 28 weeks of gestation showed a significant reduction in moderate or severe CP (2.7 vs $6.0 \%$; RR: $0.45 ; 95 \% \mathrm{Cl}: 0.23-0.87)$. The risk of death was slightly higher in the magnesium group (9.5 vs $8.5 \%$; RR: 1.12 ; $95 \% \mathrm{Cl}: 0.85-1.47)$, but nonsignificant. Exclusion of children with major congenital anomalies discovered after birth slightly lowered the relative risk of the primary outcome and attenuated the relative risk of death but had minimal effect on the relative risk of $C P$.

\section{Systematic Reviews/Meta-analyses}

A systematic review (D oyle et al $)^{23}$ that assessed the effects of $\mathrm{M} \mathrm{gSO}_{4}$ as a fetal neuroprotective agent when given to women (less than 37 weeks of gestation) considered at risk of preterm birth included five randomized controlled trials ( M agNET, BEAM, ACTOMgSO 4 , PREMAG and MAGPIE) with 6,145 fetuses. The first four trials were specifically designed to evaluate the neuroprotective effect of $\mathrm{MgSO}_{4}$, although one study ( $\mathrm{MagNET}$ ) also had a tocolytic arm. The fifth study (M A GPIE) was designed to assess the efficacy of $\mathrm{M} \mathrm{gSO}_{4}$ for prevention of seizures in women with pre-eclampsia. The primary outcomes were pediatric mortality, $\mathrm{CP}$, and the combination of mortality or $\mathrm{CP}$. A ntenatal $\mathrm{M} \mathrm{gSO}_{4}$ therapy given to women at risk of preterm birth substantially reduced the risk of $\mathrm{CP}$ (overall RR: $0.69 ; 95 \% \mathrm{Cl}: 0.54-0.87 ; p=0.002$; neuroprotection trials subgroup RR: $0.71 ; 95 \% \mathrm{Cl}: 0.55-0.91 ; p=0.006)$. The overall absolute risk of $\mathrm{CP}$ was $3.7 \%$ for fetuses exposed to $\mathrm{M} \mathrm{gSO}_{4}$ vs $5.4 \%$ for unexposed fetuses, giving an absolute risk reduction of $1.7 \%$. The number needed to treat (NNT) to prevent one case of $\mathrm{CP}$ was 63 (95\% Cl: 43-155). There was a significant reduction in the rate of substantial gross motor dysfunction (overall RR: $0.61 ; 95 \% \mathrm{Cl}: 0.44-0.85$; $p=0.003$; neuroprotection trials group R R: $0.60 ; 95 \% \mathrm{Cl}$ : $0.43-0.83 ; p=0.002$ ). There was no significant effect of antenatal $\mathrm{M} \mathrm{gSO}_{4}$ on total pediatric mortality (RR: $1.01 ; 95 \%$ $\mathrm{Cl}$ : 0.82-1.23; five trials), or on other neurologic impairments or disabilities in the first few years of life. For the overall group of five trials, antenatal $\mathrm{MgSO}_{4}$ had no significant effect on the combined rates of mortality or $C P$, except in the studies where the primary intent was neuroprotection, where there was a significant reduction in death or CP (RR: $0.85 ; 95 \% \mathrm{Cl}: 0.74-0.98$; four trials 4,446 infants).

The meta-analysis published by Conde-A gudelo and Romero ${ }^{5}$ included the same trials as the Cochrane review, with 5,357 infants. The aim was to determine whether $\mathrm{M} \mathrm{gSO}_{4}$ administered to women at risk of preterm delivery before 34 weeks of gestation may reduce the risk of CP. Like the Cochrane review, this study came to similar conclusions. A ntenatal $\mathrm{MgSO}_{4}$ was associated with a significant reduction in the risk of CP (RR: $0.69 ; 95 \% \mathrm{Cl}$ : 0.55-0.88), moderate or severe CP (RR: $0.64 ; 95 \% \mathrm{Cl}: 0.44$ 0.92 ), and substantial gross motor dysfunction (RR: 0.60 ; $95 \% \mathrm{Cl}: 0.43-0.83)$. The absolute risk of $\mathrm{CP}$ was $3.9 \%$ for fetuses exposed to $\mathrm{M} \mathrm{gSO}_{4}$ vs $5.6 \%$ for unexposed fetuses. The number of women at risk of preterm delivery less than 34 weeks of gestation who needed to be treated with magnesium rather than with placebo to prevent one case of $\mathrm{CP}$ in their children was 52 (95\% Cl: 31-154). There was no significant effect on pediatric mortality (RR: $1.01 ; 95 \%$ $\mathrm{Cl}: 0.89-1.14)$. This last finding suggests the reduced risk of $\mathrm{CP}$ does not appear to be due to selective mortality of $\mathrm{M} \mathrm{gSO}_{4}$-exposed infants. $\mathrm{M} \mathrm{gSO}_{4}$ therapy had no significant effect on the risk of major maternal complications, adverse neonatal outcomes and other infant neurodevelopmental outcome.

The meta-analysis published by Costantine ${ }^{11}$ included the same five trials, but separate analyses were performed according to the gestational age at randomization [less than 32 to 34 (5 trials, 5,235 infants) and less than 30 weeks (3 trials, 3,107 infants) ]. A ntenatal exposure to $\mathrm{M} \mathrm{gSO}_{4}$ at less than 32 to 34 weeks significantly reduced the rates of CP (RR: $0.70 ; 95 \% \mathrm{Cl}: 0.55-0.89$ ), and moderate-severe $C P$ (RR: $0.60 ; 95 \% \mathrm{Cl}: 0.43-0.84)$, without an evident increase in the risk of death (RR: $1.01 ; 95 \% \mathrm{Cl}: 0.89-1.14$ ). For less than 30 weeks group similar results were obtained. The primary outcome of this meta-analysis was a composite outcome of perinatal or infant death or $\mathrm{CP}$ among survivors. This combination is necessary since $C P$ and death are 
competing outcomes. Overall, in utero exposure to $\mathrm{M} \mathrm{gSO}_{4}$ did not reduce the rate of death or CP (RR: $0.92 ; 95 \% \mathrm{Cl}$ : 0.83-1.03), but when only neuroprotection trials were analyzed (4 trials, 4,324 infants) they observed that $\mathrm{M} \mathrm{gSO}_{4}$ significantly reduces this outcome. The NNT was 46 (95\% $\mathrm{Cl}$ : 26-287) for infants exposed to magnesium in utero before 30 weeks, and 56 (95\% Cl: 34-164) for less than 32 to 34 weeks. This review provides reassurance for obstetricians that antenatal exposure to $\mathrm{MgSO}_{4}$ did not increase the risk of perinatal/infant death. Moreover, it demonstrated beneficial effects of in utero exposure for those before 32 to 34 weeks as well as before 30 weeks. So, it does not appear that treatment should be restricted to the latter. The findings of these three systematic reviews/metaanalyses are summarized in Table 2.

Although minor maternal complications were more common associated with $\mathrm{M} \mathrm{gSO}_{4}$ therapy, there were no significant differences between magnesium and placebo control groups in severe maternal complications, including death, cardiac arrest and respiratory failure in trials or metaanalysis. ${ }^{25}$

\section{International Guidelines}

$\mathrm{No}$ standard approach has been established for use of $\mathrm{M} \mathrm{gSO}_{4}$ for neuroprotection. The A merican College of Obstetricians and Gynecologists encourages physicians electing to use $\mathrm{MgSO}_{4}$ for fetal neuroprotection to develop specific guidelines around the issues of inclusion criteria, dosage, concurrent tocolysis, and monitoring in accordance with one of the larger trials. ${ }^{25}$

The A ntenatal M agnesium Sulfate for N europrotection Guideline Development Panel recommends $\mathrm{M} \mathrm{gSO}_{4}$ only at less than 30 weeks of gestation. They use a $4 \mathrm{gm}$ loading intravenous dose (20-30 minutes) and a $1 \mathrm{gm} / \mathrm{h}$ maintenance dose, with no immediate repeat, until birth or for 24 hours. ${ }^{26}$

The Society of Obstetricians and Gynecologists of Canada recommends that antenatal $\mathrm{M} \mathrm{gSO}_{4}$ administration should be considered for fetal neuroprotection when women present at $\leq 31+6$ weeks with imminent preterm birth (active labor with cervical dilatation $\geq 4 \mathrm{~cm}$, with or without preterm prelabor rupture of membranes) and/or planned preterm birth for fetal or maternal indications. They use a $4 \mathrm{gm}$ intravenous loading dose, over 30 minutes, followed by a $1 \mathrm{gm} / \mathrm{h}$ maintenance infusion until birth. ${ }^{27}$

\section{CONCLUSION}

Preterm birth is a risk factor for $\mathrm{CP}$, and the magnitude of the risk is inversely correlated with gestational age at birth. $\mathrm{CP}$ is a leading cause of chronic childhood disability, with profound medical, emotional, and economic consequences. $\mathrm{CP}$ is permanent and can result in severe sequelae for the infant, significantly affecting the family and the society. In order to reduce the impact of CP from very preterm birth, efforts must be focused on primary prevention.

$B$ rain protection remains a challenge in infants who are born very preterm. $\mathrm{MgSO}_{4}$ has been one of the rare pharmacologic interventions used in randomized control trials for its potential neuroprotective properties. The mechanisms by which magnesium might reduce or prevent neuronal damage have not been fully elucidated. While it is plausible that $\mathrm{MgSO}_{4}$ could provide neuroprotection through mechanisms, such as reduced vascular instability and hypoxic damage, and reductions in cytokine/excitatory amino acid-induced damage, further study is needed to clarify its role in these processes. ${ }^{15}$

Given the relative safety of $\mathrm{M} \mathrm{gSO}_{4}$ for the mother, the lack of evident risk regarding infant mortality, and the familiarity of most obstetricians with its use, $\mathrm{M} \mathrm{gSO}_{4}$ can be considered for neuroprophylaxis in the setting of preterm birth. The ideal candidate and the specific protocol should be decided upon at the institution level.

Comparisons between the published trials are made difficult by differences in inclusion criteria, population studied, magnesium sulfate regimens, gestational age and evaluated outcomes, and therefore, conclusions need to be interpreted cautiously. The appropriate total dosage,

Table 2: Systematic review/meta-analyses: Results ${ }^{24}$

\begin{tabular}{|c|c|c|c|c|c|}
\hline Study & Gestational age & RR of cerebral palsy & NNT & $\begin{array}{l}\text { RR of gross } \\
\text { motor dysfunction }\end{array}$ & $\begin{array}{l}\mathrm{RR} \text { of total pediatric } \\
\text { mortality }\end{array}$ \\
\hline Doyle et al ${ }^{23}$ & $<37$ weeks & $\begin{array}{l}0.69 \\
(95 \% \mathrm{Cl}: 0.54-0.87)\end{array}$ & $\begin{array}{l}63 \\
(95 \% \text { Cl: 43-155) }\end{array}$ & $\begin{array}{l}0.61 \\
(95 \% \mathrm{Cl}: 0.44-0.85)\end{array}$ & $\begin{array}{l}1.01 \\
(95 \% \mathrm{Cl}: 0.82-1.23)\end{array}$ \\
\hline $\begin{array}{l}\text { Conde-Agudelo } \\
\text { and Romero } 5\end{array}$ & $<34$ weeks & $\begin{array}{l}0.69 \\
(95 \% \mathrm{Cl}: 0.55-0.88)\end{array}$ & $\begin{array}{l}52 \\
\text { (95\% Cl: 31-154) }\end{array}$ & $\begin{array}{l}0.60 \\
(95 \% \mathrm{Cl}: 0.43-0.83)\end{array}$ & $\begin{array}{l}1.01 \\
(95 \% \mathrm{Cl}: 0.89-1.14)\end{array}$ \\
\hline \multirow[t]{2}{*}{ Costantine et al ${ }^{11}$} & $<32-34$ weeks & $\begin{array}{l}0.70 \\
(95 \% \mathrm{Cl}: 0.55-0.89)\end{array}$ & $\begin{array}{l}56 \\
\text { (95\% Cl: 34-164) }\end{array}$ & - & $\begin{array}{l}1.01 \\
(95 \% \mathrm{Cl}: 0.89-1.14)\end{array}$ \\
\hline & $<30$ weeks & $\begin{array}{l}0.69 \\
(95 \% \mathrm{Cl}: 0.52-0.92)\end{array}$ & $\begin{array}{l}46 \\
\text { (95\% Cl: 26-287) }\end{array}$ & - & $\begin{array}{l}1.00 \\
(95 \% \mathrm{Cl}: 0.87-1.15)\end{array}$ \\
\hline
\end{tabular}

$\mathrm{Cl}$ : Confidence interval; $\mathrm{RR}$ : R elative risk 
Magnesium Sulfate: Fetal Neuroprotective Role in Reducing the Risk of Cerebral Palsy

infusion period, need for retreatment and therapeutic window for neuroprotection are still not known.

Diagnostic techniques, such as magnetic resonance imaging of the brain might help to determine how magnesium affects the brain, particularly the motor system, to reduce the rate of adverse motor outcomes.

A reported economic analysis of magnesium neuroprophylaxis for women at risk for preterm birth less than 32 weeks of gestation concluded that $\mathrm{M} \mathrm{gSO}_{4}$ therapy is costeffective. ${ }^{28}$

Encouraging results from systematic reviews and metaanalyses using several randomized controlled trials confirmed that administration of $\mathrm{MgSO}_{4}$ improves the neurodevelopmental future of preterm infants.

These results suggest that antenatal $\mathrm{M} \mathrm{gSO}_{4}$ could be used for the primary prevention of CP in preterm infants. However, since $C P$ is a result of multiple interacting risk factors rather than of a single cause, it is unlikely that antenatal $\mathrm{M} \mathrm{gSO}_{4}$ administration alone can prevent all cases of this illness in preterm infants.

\section{REFERENCES}

1. Bax M, Goldstein M, Rosenbaum, et al. Proposed definition and classification of cerebral palsy. Dev Med Child Neurol 2005;47(8):571-76.

2. M oster D, Lie RT, M arkestad T. L ong-term medical and social consequences of preterm birth. N Engl J M ed 2008;359(3): 262-73.

3. Rouse DJ, Hirtz DG, Thom E, et al. A randomized, controlled trial of magnesium sulfate for the prevention of cerebral palsy. N Engl J Med 2008;359(9):895-905.

4. Vincer M J, A llen A C, Joseph KS, et al. Increasing prevalence of cerebral palsy among very preterm infants: A populationbased study. Pediatrics 2006; 118(6):1621-26.

5. Conde-A gudelo A, R omero R. A ntenatal magnesium sulfate for the prevention of cerebral palsy in preterm infants less than 34 weeks' gestation: A systematic review and meta-analysis. A m J Obstet Gynecol 2009;200(6):595-609.

6. Degos V, Loron G, M antz J, et al. Neuroprotective strategies for the neonatal brain. A nesth A nalg 2008;106(6):1670-80.

7. Costantine M M, Drever $N$. A ntenatal exposure to magnesium sulfate and neuroprotection in preterm infants. Obstet Gynecol Clin N orth A m 2011; 38(2):351-66.

8. Hankins GD, Speer M. Defining the pathogenesis and pathophysiology of neonatal encephal opathy and cerebral pal sy. Obstet Gynecol 2003;102(3):628-36.

9. Crowther CA, Hiller JE, D oyle LW, et al. Effect of magnesium sulfate given for neuroprotection before preterm birth: $A$ randomized controlled trial. JA M A 2003;290(20):2669-76.

10. Burd I, B reen K, Friedman A, et al. M agnesium sulfate reduces inflammation-associated brain injury in fetal mice. A m J Obstet Gynecol 2010;202(3):292.e1-9.

11. Costantine MM, W einer SJ. Effects of antenatal exposure to magnesium sulfate on neuroprotection and mortality in preterm infants: A meta-analysis. Obstet Gynecol 2009;114(2 Pt 1): 354-64.
12. N elson K B, G rether JK. C an magnesium sulfate reduce the risk of cerebral palsy in very low birthweight infants? Pediatrics 1995; 95(2):263-69.

13. Costa F da S, L opes L, B rennecke S. M agnesium sulphate for fetal neuroprotection. Rev Bras Ginecol Obstet 2011;33(6): 265-70.

14. Heyborne K, Bowes WA. The use of antenatal magnesium sulfate for neuroprotection for infants born prematurely. F1000 Med Rep 2010;2:78.

15. M ercer B M , M erlino A A . M agnesium sulfate for preterm labor and preterm birth. Obstet Gynecol 2009;114(3):650-68.

16. Bhat M A, Charoo BA, B hat JI, et al. M agnesium sulfate in severe perinatal asphyxia: A randomized, placebo-controlled trial. Pediatrics 2009;123(5):764-69.

17. Doyle LW, Crowther CA, M iddleton P, et al. Magnesium sulphate for women at risk of preterm birth for neuroprotection of the fetus. Cochrane Database Syst Rev 2009(1):CD 004661.

18. M ittendorf R, D ambrosia J, Pryde PG, et al. A ssociation between the use of antenatal magnesium sulfate in preterm labor and adverse health outcomes in infants. A m J Obstet Gynecol 2002;186(6):1111-18.

19. Magpie Trial Follow-Up Study Collaborative Group. The $M$ agpie Trial: A randomised trial comparing magnesium sulphate with placebo for pre-eclampsia. Outcome for women at 2 years. BJ OG 2007;114(3):300-09.

20. Magpie Trial Follow-Up Study Collaborative Group. The $M$ agpie Trial: A randomised trial comparing magnesium sulphate with placebo for pre-eclampsia. Outcome for children at 18 months. BJOG 2007;114(3):289-99.

21. M arret $S, M$ arpeau $L$, Zupan-Simunek $V$, et al. M agnesium sulphate given before very-preterm birth to protect infant brain: The randomised controlled PREMAG trial BJOG 2007;114(3):310-18.

22. $M$ arret $S, M$ arpeau $L, B$ enichou J. B enefit of magnesium sulfate given before very preterm birth to protect infant brain. Pediatrics 2008;121(1):225-26.

23. Doyle LW, Crowther CA, M iddleton P, et al. A ntenatal magnesium sulfate and neurologic outcome in preterm infants: A systematic review. Obstet Gynecol 2009;113(6):1327-33.

24. Goojha C. Can magnesium sulphate provide neuroprotection in preterm infants? A literature review. RCSIsmj 2011;4(1): 46-52.

25. A merican College of O bstetricians and Gynecologists Comitee on Obstetric Practise, Society for $M$ aternal-Fetal M edicine. Comittee Opinion No. 455. Magnesium sulfate before anticipated preterm birth for neuroprotection. Obstet Gynecol 2010;115:669.

26. The A ntenatal Magnesium Sulphate for Neuroprotection Guideline Development Panel. A ntenatal magnesium sulphate prior to preterm birth for neuroprotection of the fetus, infant and child: N ational clinical practice guidelines. The U niversity of A delaide. 2010.

27. M agee L, Saw chuck D, Synnes A, et al. SO GC Clinical Practice Guideline. Magnesium sulphate for fetal neuroprotection. J Obstet Gynaecol Can 2011;33(5):516-29.

28. Cahill AG, Odibo AO, Stout MJ, et al. Magnesium sulfate therapy for the prevention of cerebral palsy in preterm infants: A decision-analytic and economic analysis. A m J O bstet Gynecol 2011;205(6):542.e1-7. 


\section{ABOUT THE AUTHORS}

Simona Constantinescu (Corresponding Author)

Neonatologist and Head, Department of Neonatology, 'Elias' Emergency U niversity Hospital, M arasti 17, Bucharest, Romania Phone: +40213161640, e-mail: simconst69@gmail.com

\section{Margareta Denes}

Specialist, Department of Obstetrics and Gynecology, 'Elias' Emergency U niversity Hospital, Bucharest, Romania

\section{Andrei Chilianu}

Senior Resident, Department of Obstetrics and Gynecology, 'Elias' Emergency University Hospital, B ucharest, Romania

\section{Radu Vladareanu}

Professor, Department of Obstetrics and Gynecology, 'Carol Davila' University of M edicine and Pharmacy, 'Elias' Emergency University Hospital, Bucharest, Romania 